\title{
Impedance Spectroscopy of Vanadium Pentoxide Thin Films
}

\author{
KRYSTYNA SCHNEIDER $\mathbb{1},{ }^{1,3}$ MALGORZATA DZIUBANIUK, ${ }^{2,4}$ \\ and JAN WYRWA ${ }^{2,5}$ \\ 1.-Faculty of Computer Science, Electronics and Telecommunications, AGH University of Science \\ and Technology, Kraków, Poland. 2.-Faculty of Materials Science and Ceramics, AGH University \\ of Science and Technology, Kraków, Poland. 3.-e-mail: kryschna@agh.edu.pl. 4.-e-mail: \\ dziubaniuk@o2.pl. 5.—e-mail: jwyrwa@agh.edu.pl
}

\begin{abstract}
$\mathrm{V}_{2} \mathrm{O}_{5}$ thin films have been deposited onto an insulating support by radiofrequency (rf) reactive sputtering from a metallic vanadium target at controlled flow rates of argon-oxygen gas mixture. Glancing-incidence x-ray diffraction (GIXD) analysis and scanning electron microscopy (SEM) were used for structural and phase characterization of the obtained materials. The assputtered thin films were found to consist of orthorhombic $\mathrm{V}_{2} \mathrm{O}_{5}$ phase. Electrical properties were determined by electrochemical impedance spectroscopy (EIS) conducted over the frequency range of $0.1 \mathrm{~Hz}$ to $1.4 \mathrm{MHz}$ and temperatures ranging from room temperature (RT) to $773 \mathrm{~K}$. Between RT and $528 \mathrm{~K}$, the recorded impedance spectra were interpreted in terms of an equivalent circuit composed of a resistor and non-Debye constant-phase element (CPE) connected in parallel. In this temperature range, the material exhibited $n$-type extrinsic conductivity. The activation energy of electrical conductivity was $0.243 \pm 0.023 \mathrm{eV}$. At $528 \mathrm{~K}$, an abrupt change in resistivity was observed, interpreted as a metal-insulator transition (MIT). Above $528 \mathrm{~K}$, the equivalent circuit was composed of a resistor $(R)$ and inductor $(L)$ connected in series, typical of materials exhibiting metallic properties.
\end{abstract}

Key words: Oxide electronics, vanadium pentoxide, thin film, electrical conductivity, metal-insulator transition, defect structure

\section{INTRODUCTION}

Vanadium oxides can exist with different formal vanadium valence states, ranging from $2+$ in $\mathrm{VO}$, through $3+$ in $\mathrm{V}_{2} \mathrm{O}_{3}$ and $4+$ in $\mathrm{VO}_{2}$, to $5+$ in $\mathrm{V}_{2} \mathrm{O}_{5}$. In addition, monovalent and divalent oxides are known. The latter form either the Magnéli series $\mathrm{V}_{n} \mathrm{O}_{2 n-1}$ or the Wadsley series $\mathrm{V}_{n} \mathrm{O}_{2 n+1}$ (where $n$ is an integer).

The crystal structure of the Magnéli and Wadsley phases is usually interpreted as rutile $\mathrm{VO}_{2}$ slabs separated by shear planes at a distance determined by the parameter $n$. Vanadium oxides have been determined to exhibit fascinating electrical, magnetic, and optical properties. ${ }^{1}$ A remarkable

(Received December 30, 2018; accepted March 21, 2019; published online April 8, 2019) phenomenon observed for the majority of these oxides is the abrupt change in these properties at a specific temperature-a phenomenon known as the metal-insulator transition (MIT). ${ }^{2}$

Among vanadium oxide materials, vanadium pentoxide is particularly noteworthy due to its outstanding physical and chemical properties. Its good chemical and thermal stability as well as excellent thermoelectric properties make $\mathrm{V}_{2} \mathrm{O}_{5}$ a promising material for use in oxide electronics. ${ }^{3}$ It has found numerous applications, including in electrical and optical switching devices, critical temperature sensors, heterogeneous catalysis, gas sensors, ${ }^{5}$ supercapacitors ${ }^{6}$ electrochromic devices, ${ }^{7}$ optical switching devices ${ }^{8,9}$ reversible cathode materials for $\mathrm{Li}$ batteries, ${ }^{7,10}$ and as a thermoresistive material in thermal infrared detectors. ${ }^{11}$ 
Due to the layered structure of $\mathrm{V}_{2} \mathrm{O}_{5}$ and the weak bonds between its layers, it is possible to extract a piece of this material that is only several layers thick $(\sim \mathrm{nm})$ or even a monolayer. Such a layer retains the same properties as a thin film of $\mathrm{V}_{2} \mathrm{O}_{5}$, including the ability to undergo a metal-insulator transition. Since graphene (a single layer of graphite) exhibits remarkable properties that differ from those of its bulk counterpart, it would be interesting to establish whether-by analogy-certain noteworthy properties can be observed for a single layer of vanadium pentoxide. ${ }^{12}$

Despite its significance in both fundamental and applied research, there are unresolved issues concerning the electrical properties of vanadium pentoxide, especially the MIT phenomenon. ${ }^{13,14}$ Pergament et al. ${ }^{15}$ argued that the term "metalinsulator transition" is not entirely correct in the context of this oxide. Furthermore, the precise mechanism of the MIT in $\mathrm{V}_{2} \mathrm{O}_{5}$, if this transition is assumed to indeed occur, is still a matter of debate, ${ }^{14}$ and a theoretical understanding that would make it possible to predict the transition temperature has not yet been reached. ${ }^{16}$

In the work presented herein, both the structural and electrical properties of vanadium pentoxide thin films were examined.

\section{EXPERIMENTAL PROCEDURES}

\section{Sample Preparation}

Vanadium oxide thin films were deposited by radiofrequency (rf) reactive sputtering $(2 \mathrm{~h})$ from a metallic V target supplied by Kurt J. Lesker Company (vanadium, 4.00 inch diameter, 0.124 inch thickness, $99.9 \%$ purity, compatible with most standard guns), in a controlled atmosphere with argonoxygen gas flow. Fused silica, $\mathrm{Si}$, and a conductometric sensor substrate (type CC1.W, BVT Technologies, Czech Rep.) served as the substrate. A deposition run was carried out under predefined conditions of total gas pressure, constant oxygen $\left(0.7 \mathrm{~cm}^{3} / \mathrm{s}\right)$ and argon $\left(6.7 \mathrm{~cm}^{3} / \mathrm{s}\right)$ flows, constant input power $(200 \mathrm{~W})$, and voltage $(1000 \mathrm{~V})$ as well as controlled substrate temperature $\left(T_{\mathrm{sub}}=673 \mathrm{~K}\right)$. Figure 1 shows a schematic of the rf setup.

\section{Structural and Morphological Studies}

The phase composition of the samples was determined by x-ray diffraction (XRD) analysis at glancing incidence (GIXD) using a JASCO NRS-4100 spectrometer equipped with a laser emitting at wavelength of $457 \mathrm{~nm}$ as excitation source.

Crystallographic studies were carried out by GIXD using a Philips X'Pert diffractometer at $2 \theta$ angles in the range of $20^{\circ}$ to $80^{\circ}$ and $\mathrm{Cu} \mathrm{K}_{\alpha}$ filtered radiation.

Crystallite size $\left(d_{\mathrm{XRD}}\right)$ was determined from the $\mathrm{x}$ ray broadening of selected peaks using the Scherrer equation:

$$
d_{\mathrm{XRD}}=\frac{0.9 \lambda}{\Delta(2 \theta) \cos \theta},
$$

where $\lambda=0.154056 \mathrm{~nm}$ is the used $\mathrm{x}$-ray wavelength $\left(\mathrm{Cu} \mathrm{K}_{\alpha}\right), 2 \theta$ denotes the broadening of the XRD peak at half its maximum intensity, and $\theta$ represents the Bragg diffraction angle. The parameter $d_{\mathrm{XRD}}$ was determined for the six most pronounced peaks, yielding values of $20.0 \pm 1.8 \mathrm{~nm}$.

The microstructure of the films was studied using scanning electron microscopy (Nova 200, FEI Europe B.V.). An energy-dispersive x-ray (EDAX) spectrometer coupled with the scanning electron microscope was used to determine the chemical composition of the samples.

\section{Impedance Measurements}

Impedance measurements were performed by means of impedance spectroscopy using a computer-controlled Solartron 1260 frequency response analyzer and 1294 dielectric interface. The obtained impedance spectra were analyzed using the ZPLOT software package provided by Solartron. The measurements were carried out over the temperature range of $298 \mathrm{~K}$ to $773 \mathrm{~K}$ and within the frequency range of $0.1 \mathrm{~Hz}$ to $1 \mathrm{MHz}$. The amplitude of the sinusoidal voltage was $10 \mathrm{mV}$.

\section{RESULTS AND DISCUSSION}

\section{Structural and Microstructural Characteristics}

Figure 2 presents a typical XRD pattern recorded for the sample annealed for $1.44 \mathrm{ks}(4 \mathrm{~h})$ in argon atmosphere at $673 \mathrm{~K}$. X-ray diffraction analysis of the samples revealed the presence of the orthorhombic phase of $\mathrm{V}_{2} \mathrm{O}_{5}$.

The determined lattice parameters and crystallite size $\left(d_{\mathrm{XRD}}\right)$ are presented in Table I. The determined lattice parameters are highly consistent with data reported in literature. ${ }^{17-20}$

Figure 3 shows SEM micrographs of thin films deposited on a silicon substrate in as-sputtered state (Fig. 3a) and after $72 \mathrm{ks}(20 \mathrm{~h})$ of sintering at $673 \mathrm{~K}$ (Fig. 3b). As seen, the as-sputtered thin films (Fig. 3a) were polydisperse, and the grains were mostly columnar in shape $(565 \pm 100 \mathrm{~nm}$ length, $220 \pm 40 \mathrm{~nm}$ diameter). On the other hand, after sintering (Fig. 3b), they were rather spherical (mean diameter $500 \pm 75 \mathrm{~nm}$ ). Chemical analysis performed by energy-dispersive spectrometry (EDS) (Fig. 4) revealed the presence of pronounced peaks originating from the silicon support and much smaller peaks corresponding to oxygen and vanadium elements.

\section{Electrical Properties}

Figure 5 shows the impedance spectra determined at lower temperatures ( $373 \mathrm{~K}$ to $523 \mathrm{~K}$ ), 


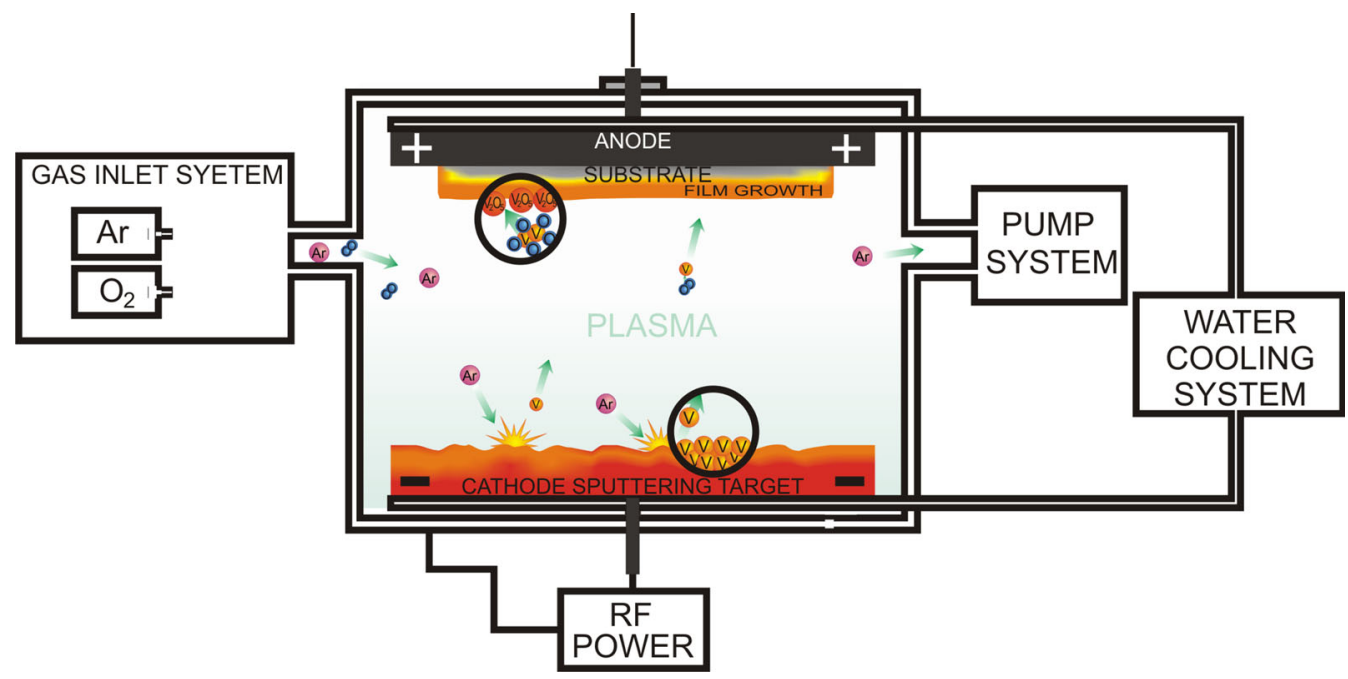

Fig. 1. Schematic of rf deposition chamber.

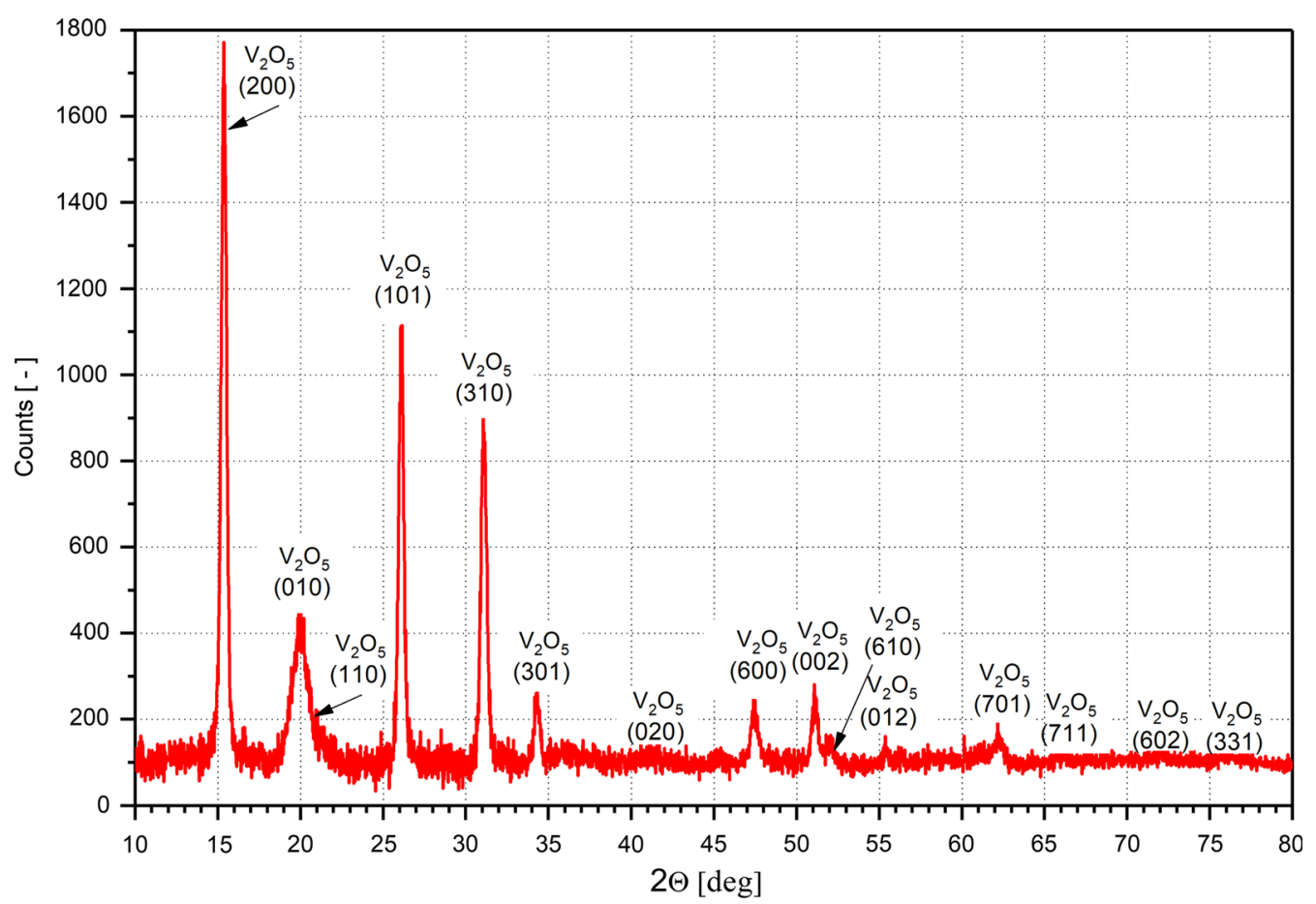

Fig. 2. X-ray diffraction pattern for $\mathrm{V}_{2} \mathrm{O}_{5}$ thin film.

Table I. Results of XRD analysis

\begin{tabular}{|c|c|c|c|c|c|}
\hline & \multirow[b]{2}{*}{ Crystal structure } & \multicolumn{3}{|c|}{ Lattice parameter } & \multirow[b]{2}{*}{$d_{\text {XRD }}(\mathbf{n m})$} \\
\hline & & $a(\mathbf{n m})$ & $b(\mathbf{n m})$ & $c(\mathbf{n m})$ & \\
\hline This work & $\mathrm{V}_{2} \mathrm{O}_{5}$ & $1.149 \pm 0.002$ & $0.436 \pm 0.003$ & $0.357 \pm 0.005$ & $20.0 \pm 1.8$ \\
\hline Ref. 17 & Orthorhombic & $1.152 \pm 0.002$ & $0.437 \pm 0.004$ & $0.352 \pm 0.009$ & \\
\hline Ref. 18 & Pmmn & 1.148 & 0.436 & 0.355 & \\
\hline Ref. 19 & & 1.1519 & 0.4373 & 0.3564 & \\
\hline Ref. 20 & & 1.1512 & 0.4368 & 0.3564 & \\
\hline
\end{tabular}




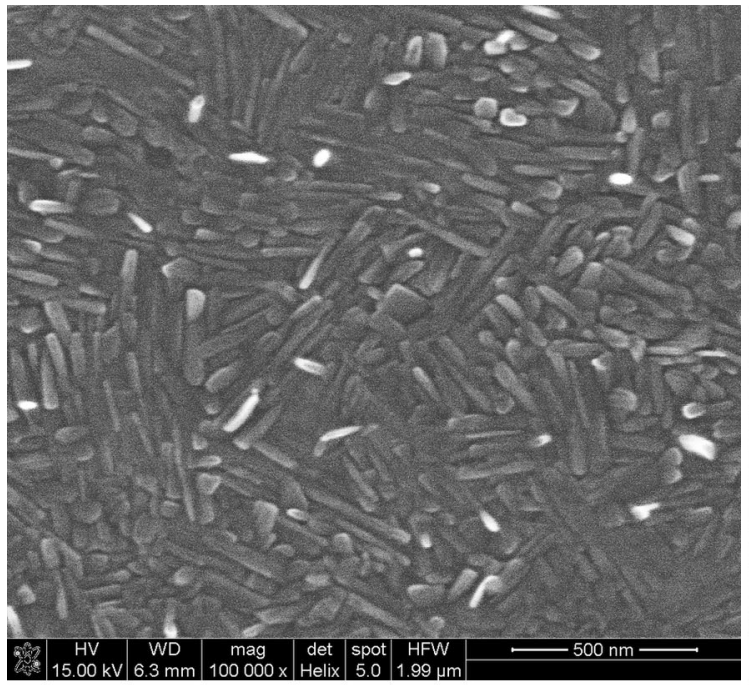

(a)

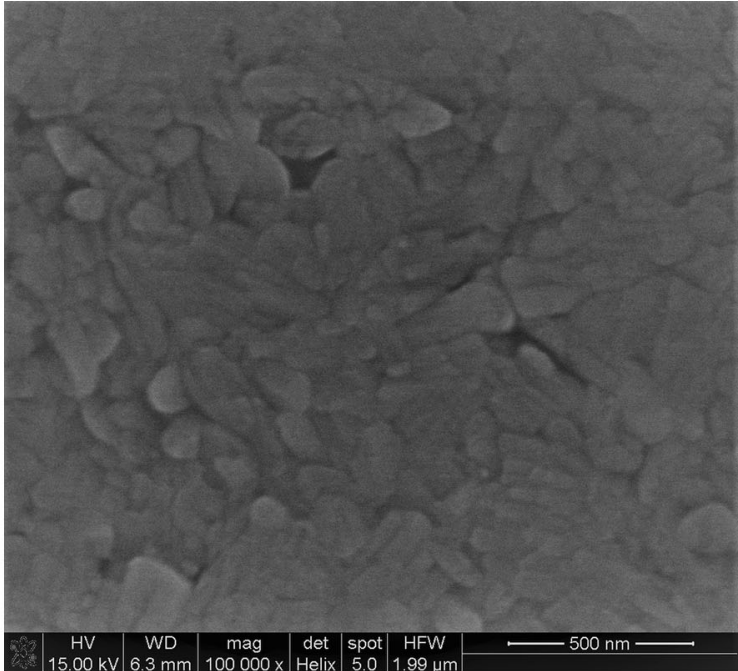

(b)

Fig. 3. SEM micrographs obtained for $\mathrm{V}_{2} \mathrm{O}_{5}$ thin films: (a) as-sputtered; (b) sintered at $673 \mathrm{~K}$ for $72 \mathrm{ks}(20 \mathrm{~h})$.

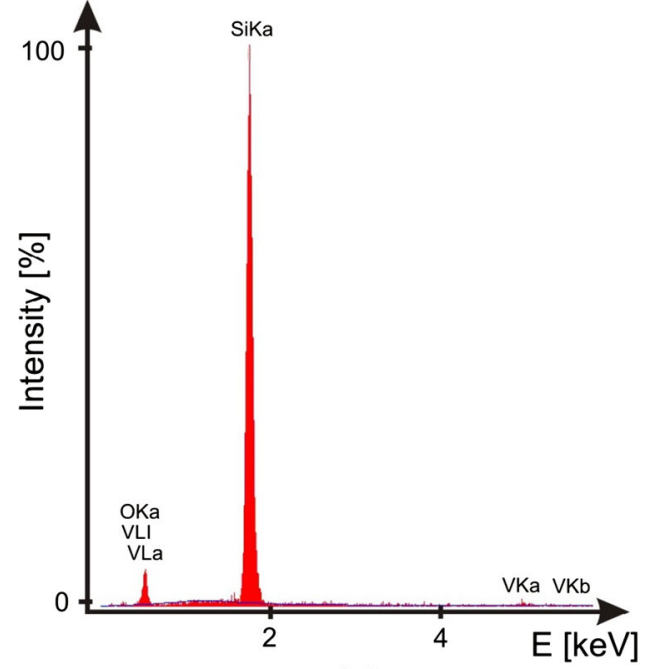

(a)

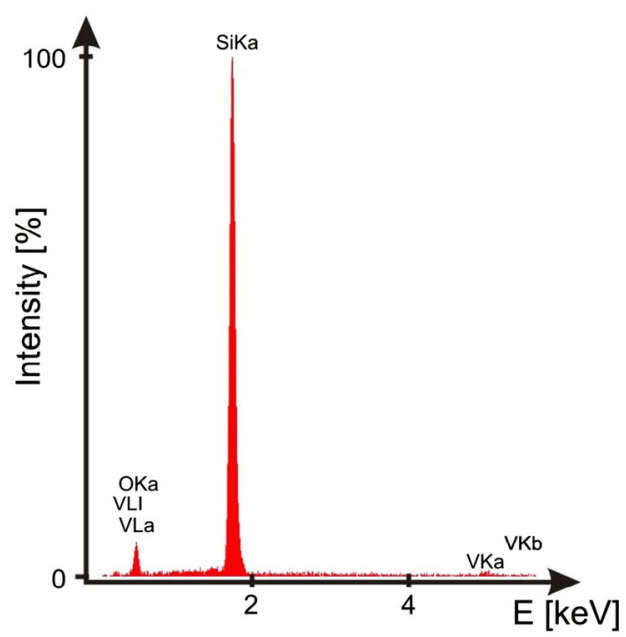

(b)

Fig. 4. EDS spectra recorded for $\mathrm{V}_{2} \mathrm{O}_{5}$ thin films: (a) as-sputtered; (b) sintered at $673 \mathrm{~K}$ for $72 \mathrm{ks}(20 \mathrm{~h})$.

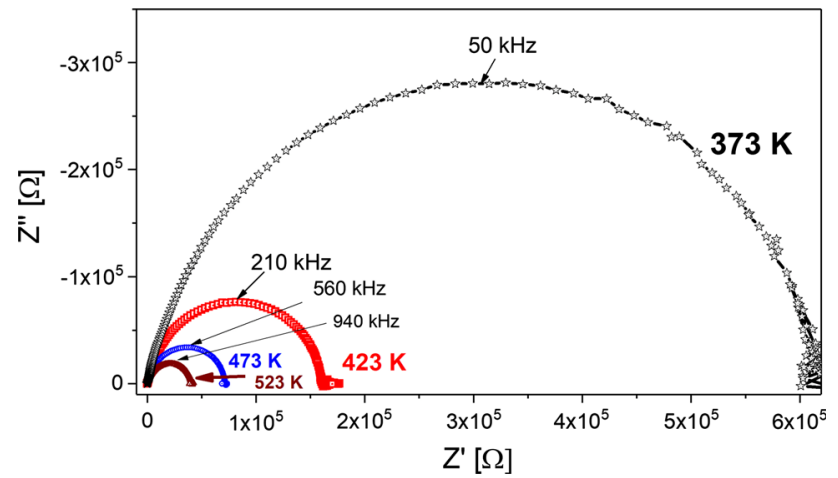

Fig. 5. Nyquist plots of $\mathrm{V}_{2} \mathrm{O}_{5}$ thin film at several temperatures. presented on the complex plane of $Z^{\prime \prime}$ versus $Z^{\prime}$ (Nyquist plot).

The plots can be interpreted in terms of an equivalent circuit composed of a resistor and a non-Debye constant-phase element (CPE) connected in parallel (Fig. 6a).

A decrease in ohmic resistance is observed with increasing temperature-a behavior typical of semiconducting materials.

The impedance spectra observed at higher temperatures (above $528 \mathrm{~K}$ ) were starkly different. An example of such a spectrum is presented in Fig. 7 .

In this case, the imaginary part of the impedance $\left(Z^{\prime \prime}\right)$ assumed positive values, indicating a nonnegligible contribution of inductance. The presented 


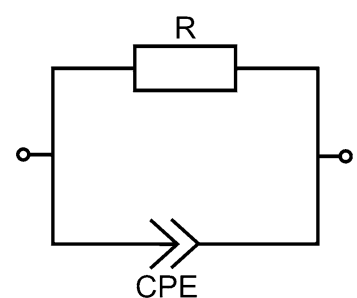

(a)

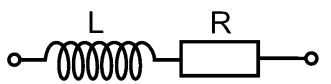

(b)

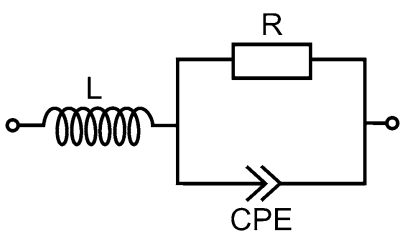

(c)

Fig. 6. Equivalent circuits used for interpretation of impedance spectra, (a) at lower temperatures (below $528 \mathrm{~K}$ ); (b) and (c) at higher temperatures (above $528 \mathrm{~K}$ ); (b) model 1 and (c) model 2.

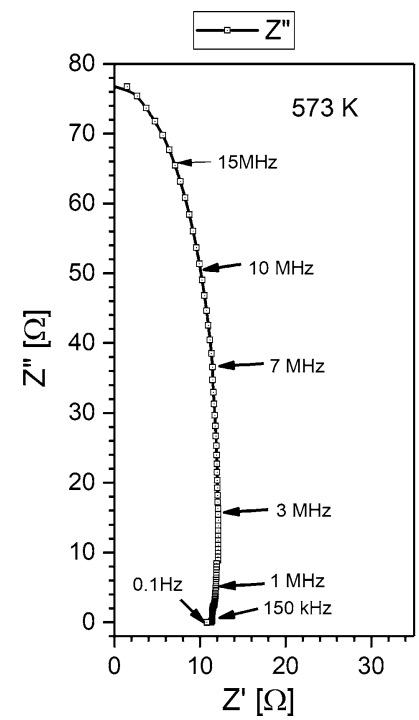

Fig. 7. Nyquist plots of $\mathrm{V}_{2} \mathrm{O}_{5}$ thin film at $573 \mathrm{~K}$.

spectrum can be interpreted using an equivalent circuit composed of a resistor $(R)$ and inductor $(L)$ connected in series (Fig. 6b).

Figure 8 illustrates the Nyquist plots on the complex admittance plane at $573 \mathrm{~K}, 623 \mathrm{~K}$, and $673 \mathrm{~K}$. The lack of experimental points above the $Y^{\prime}$ axis suggests that the contribution of capacitive elements (Debye capacitor and CPE) is negligible.

The inductance $(L)$ can be determined from the dependence of the imaginary part of the impedance $\left(Z^{\prime \prime}\right)$ on the angular frequency $(\omega)$ :

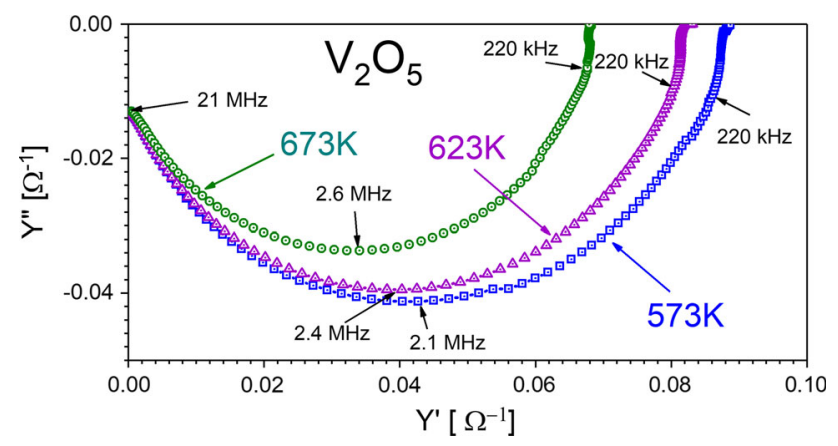

Fig. 8. Experimental spectra at $573 \mathrm{~K}, 623 \mathrm{~K}$, and $673 \mathrm{~K}$ presented on complex admittance plane.

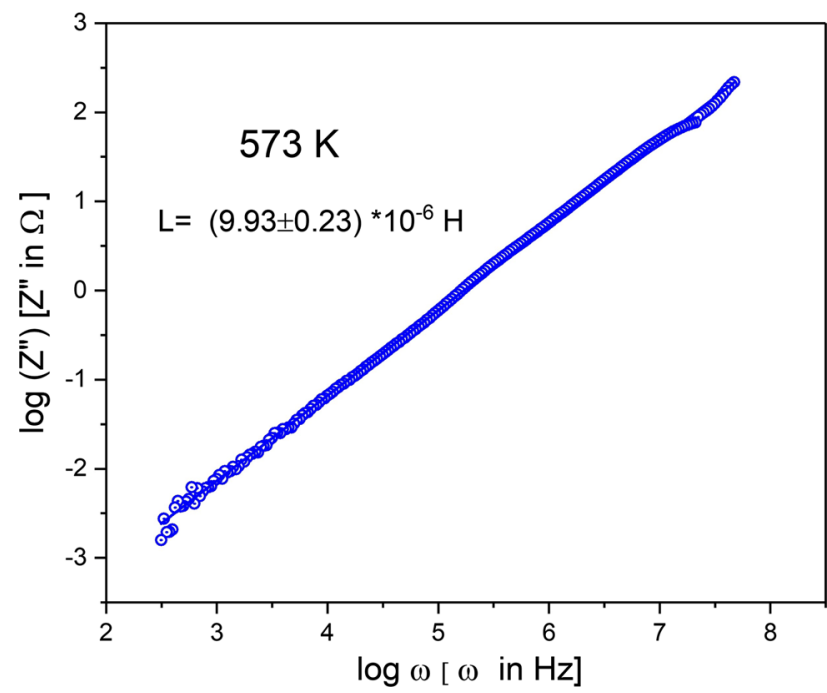

Fig. 9. Dependence of $Z^{\prime}$ on $\omega$.

$$
Z^{\prime \prime}=j \omega L,
$$

where $\mathrm{j}$ is the imaginary unit. Figure 9 illustrates such dependence for a thin film at $573 \mathrm{~K}$.

Figure 10 shows the experimental admittance spectrum (points) and theoretical dependence corresponding to the postulated $L-R$ (model b) and $L-$ $R-\mathrm{CPE}$ (model c) equivalent circuits. Good agreement is observed in the case of the lower frequencies $(0 \mathrm{MHz}$ to $0.32 \mathrm{MHz})$ and in the case of frequencies in the range of $4.20 \mathrm{MHz}$ to $4.45 \mathrm{MHz}$ in case of model $\mathrm{b}$, and very good agreement when assuming the $L-R-\mathrm{CPE}$ equivalent circuit (model c).

Figure 11 shows an Arrhenius plot of the electrical conductivity $(\sigma)$ in the temperature range of $293 \mathrm{~K}$ to $473 \mathrm{~K}$. The experimental data satisfy a linear dependence according to the equation

$$
\sigma=\sigma_{0} \exp \left[-\frac{E_{\text {act }}}{k T}\right]
$$

where $\sigma_{0}$ is a temperature-independent parameter and $k$ is the Boltzmann constant. The increase in the electrical conductivity with temperature 


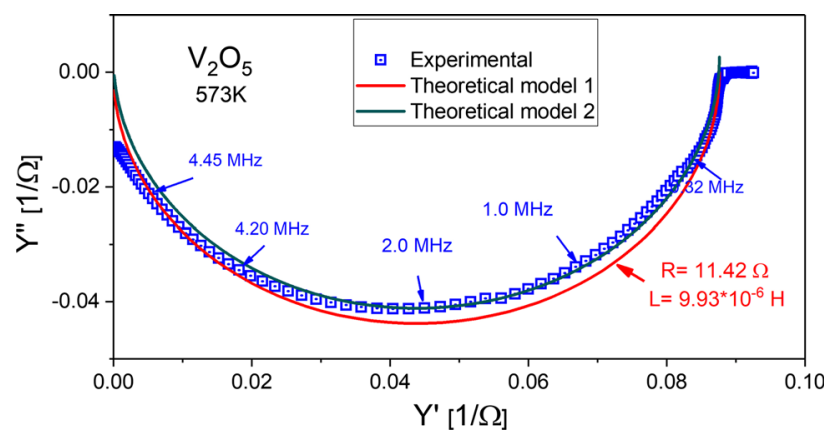

Fig. 10. Admittance spectrum of $\mathrm{V}_{2} \mathrm{O}_{5}$ thin film at $573 \mathrm{~K}$; points represent experimental data; line represents theoretical dependence for $R=11.42 \Omega, L=9.93 \times 10^{-6} \mathrm{H}$.

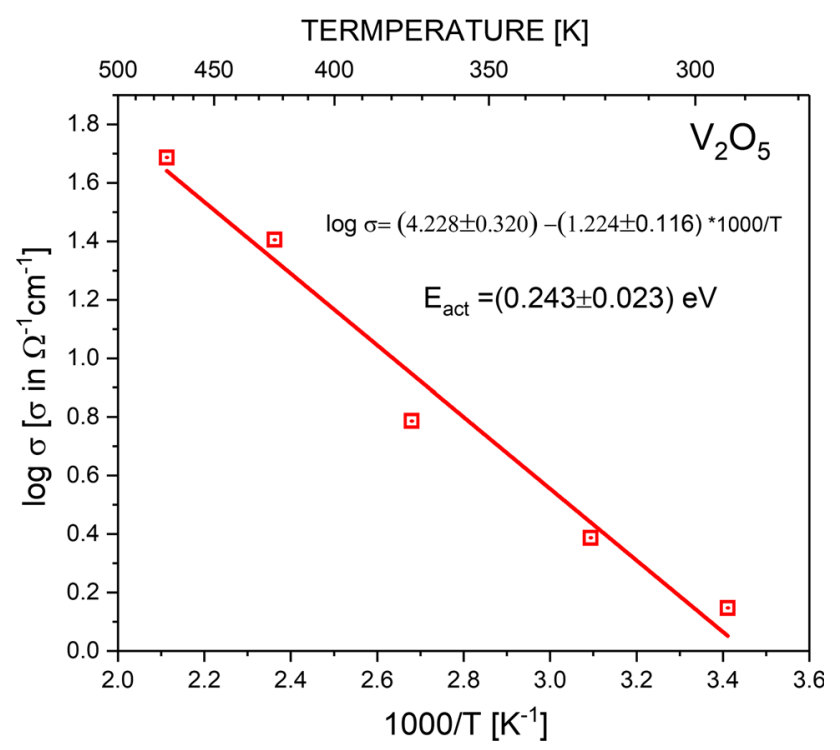

Fig. 11. Temperature dependence of electrical conductivity (Arrhenius plot) of $\mathrm{V}_{2} \mathrm{O}_{5}$.

indicates semiconducting properties in the studied temperature range. The activation energy of the electrical conductivity determined from the slope of the straight line is $0.243 \pm 0.023 \mathrm{eV}$, much lower than half the energy bandgap $\left(E_{\mathrm{g}}\right)$ of $\mathrm{V}_{2} \mathrm{O}_{5}\left(E_{\mathrm{g}}=2.3\right.$ $\mathrm{eV}^{21}$ ) predicted for the intrinsic electrical conductivity, being typical of extrinsic conductivity. The electrical properties of vanadium pentoxide are closely associated with its nonstoichiometry $(x)$. Vanadium pentoxide shows a deficit of oxygen in relation to its stoichiometric composition: $\mathrm{V}_{2} \mathrm{O}_{5-x}$. It has been reported that nonstoichiometric $x$ values result in oxygen vacancies and electrons. ${ }^{22}$ The determined activation energy $\left(E_{\text {act }}\right)$ is approximately equal to the enthalpy of electron formation, according to the reaction ${ }^{23}$

$$
\mathrm{O}_{\mathrm{O}} \Leftrightarrow \frac{1}{2} \mathrm{O}_{2(\mathrm{~g})}+\mathrm{V}_{\mathrm{O}}+2 e^{\prime}
$$

where $\mathrm{V}_{\mathrm{O}}^{*}$ denotes a doubly ionized oxygen vacancy (in Kröger-Vink point defect notation).

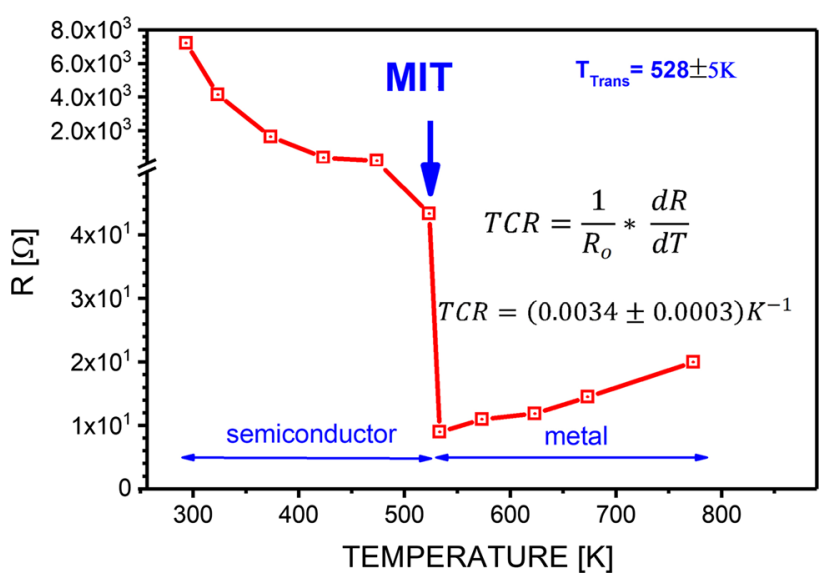

Fig. 12. Dependence of electrical resistance on temperature. Arrow shows metal-insulator transition (MIT).

\section{Metal-Insulator Transition (MIT)}

Figure 12 illustrates the dependence of the electrical resistance of $\mathrm{V}_{2} \mathrm{O}_{5}$ on temperature. Below $500 \mathrm{~K}$, the dependence indicates typical behavior related to a thermally activated process. At $T=528 \mathrm{~K}$, an abrupt change in resistance is observed. Above $528 \mathrm{~K}$, the material exhibits metallic behavior, and the resistance increases with temperature. The estimated temperature coefficient of resistance (TCR) is $3.4 \times 10^{-3} \mathrm{~K}^{-1}$, typical of metals.

This phenomenon is known as the metal-insulator transition (MIT). ${ }^{2}$ It was observed by other authors for nanostructured $\mathrm{V}_{2} \mathrm{O}_{5}$ materials (such as thin films ${ }^{24-26}$ and nanowires ${ }^{27}$ ). On the other hand, an MIT is not observed in the case of ceramic $\mathrm{V}_{2} \mathrm{O}_{5} \cdot{ }^{20}$

\section{CONCLUSIONS}

The structural and electrical properties of vanadium pentoxide thin films were studied. XRD analysis revealed that the material had orthorhombic structure with crystallite size of $20.0 \pm 1.8 \mathrm{~nm}$. The electrical properties of $\mathrm{V}_{2} \mathrm{O}_{5}$ were investigated by analyzing the complex impedance spectra at frequencies ranging from $0.1 \mathrm{~Hz}$ to $1.4 \mathrm{MHz}$ as a function of temperature in the range of $293 \mathrm{~K}$ to $773 \mathrm{~K}$, revealing two entirely different types of impedance spectrum. At temperatures below $520 \mathrm{~K}$, the impedance spectra corresponded to an equivalent circuit composed of a resistor $(R)$ and non-Debye constant-phase element (CPE) connected in parallel. In this temperature range, the material exhibited $n$-type extrinsic conductivity. The activation energy for electrical conductivity was $0.243 \pm 0.023 \mathrm{eV}$. At $528 \mathrm{~K}$, an abrupt change in resistivity was observed. This phenomenon is interpreted as the metal-insulator transition (MIT). Above $528 \mathrm{~K}$, the impedance spectra corresponded to an equivalent circuit composed of a resistor $(R)$ and inductor $(L)$, indicating that the studied sample 
exhibited metallic properties in this temperature range.

\section{ACKNOWLEDGMENTS}

This work was supported by the National Science Centre of the Republic of Poland under Grant No. 2016/23/B/ST8/00163.

\section{OPEN ACCESS}

This article is distributed under the terms of the Creative Commons Attribution 4.0 International License (http://creativecommons.org/licenses/by/4.0/), which permits unrestricted use, distribution, and reproduction in any medium, provided you give appropriate credit to the original author(s) and the source, provide a link to the Creative Commons license, and indicate if changes were made.

\section{REFERENCES}

1. J.B. Goodenough and A. Hammett, in Landolt-Börnstein Numerical Data and Functional Relationships in Science and Technology, New Series Vol. 17 Semiconductors, eds. O. Madelung, M. Schulz, and H. Weiss (Berlin: Springer, 1984), pp. 167-201 and 446-491 (and references therein -262 items).

2. N.F. Mott, Metal-Insulator Transition (London: Taylor \& Francis, 1974). https://doi.org/10.1002/crat.19750100423.

3. K. Hermann and M. Witko, in The Chemical Physics of Solid Surfaces: Oxide Surfaces, Vol. 1, ed. By D.P. Woodruff (Elsevier, Amsterdam, 2001) (Chapter 4), p. 136.

4. B. Grzybowska-Swierkosz, F. Trifiro, and J.C. Vedrine, J. Appl. Catal. A 157, 1 (1997).

5. K. Schneider, M. Lubecka, and A. Czapla, Sens. Actuators B 236, 970 (2016).

6. Y. Yang, D. Yang, M. Ki, and P. Schmuki, Chem. Commun. 47, 7746 (2011).

7. J.M. McGraw, J. Turner, and D. Ginley, J. Electrochem. Soc. 144, 1630 (1997).

8. G. Guzman, B. Yebka, J. Livage, and C. Julien, Solid State Ion. 86-88, 407 (1996).
9. A. Kumar, P. Singh, N. Kulkarni, and D. Kaur, Thin Solid Films 516, 912 (2008).

10. A.-M. Cao, J.-S. Hu, H.-P. Liang, and L.-J. Wan, Angew. Chem. Int. Ed. 44, 4391 (2005).

11. P.W. Kruse, Uncooled Thermal Imaging Arrays, Systems, and Applications (Bellingkam: SPIE Press, 2001).

12. C. Lamsal, in: Electronic thermoelectric and optical properties of vanadium oxides: $\mathrm{VO}_{2}, \mathrm{~V}_{2} \mathrm{O}_{3}$ and $\mathrm{V}_{2} \mathrm{O}_{5}$, Ph.D. New Jersey Institute of Technology and Rutgers the State University of New Jersey 2015, Archives.njit.edu.vol01/etd/ 2015.022.ptd.

13. A. Pergament, G. Stefanovich, N. Kuldin, and A. Velichko, ISRN Condens. Matter Phys. 2013, 1 (2013).

14. W.-T. Liu, J. Cao, W. Fan, Z. Hao, M.C. Martin, Y.R. Shen, J. Wu, and F. Wang, Nano Lett. 11, 466 (2011).

15. A. Pergament, G. Stefanovich, and V. Andreev, Appl. Phys. Lett. 102, 176101 (2013).

16. A.I. Pergament, ISRN Condens. Matter Phys. 2011, 1 (2011).

17. K. Schneider, K. Kluczewska, M. Dziubaniuk, and J. Wyrwa, in EYEC Monograph, Warsaw, ed. By M. Nowak (2018), pp. 227-240, ISBN 978-83-936575-5-1.

18. J.D. Hanawalt, H.W. Rinn, and L.K. Frevel, Ind. Eng. Chem. Anal. Ed. 10, 457 (1938).

19. R.W.G. Wyckoff, Crystal Structures, 2nd ed., Vol. 2 (New York: Wiley, 1964).

20. R. Enjalbert and J. Galy, Acta Crystallogr. Sect. C R. Cryst. Struct. Commun. 42, 1467 (1986).

21. A. Chakrabarti, K. Hermann, R. Druzinic, M. Witko, F. Wagner, and M. Petersen, Phys. Rev. B 59, 10583 (1999).

22. P. Kofstad, Nonstoichiometry, Diffusion and Electrical Conductivity in Binary Metal Oxides (London: Wiley, 1972).

23. K. Schneider, in Proceedings of SPIE (2016), pp. 109-1-1099.

24. P. Kang, I. Kim, S. Kim, and H.Y. Park, Appl. Phys. Lett. 98, 131907 (2011).

25. E.E. Chain, Appl. Opt. 30, 2782 (1991).

26. P. Kiri, G. Hyett, and R. Binions, Adv. Mater. Lett. 1, 86 (2010).

27. T. Wu, C.J. Patridge, S. Banerjee, and G. Sambandamurthy, in APS Meeting, March 15-19 (2010). American Physical Society. Abstract \#V16.007.

Publisher's Note Springer Nature remains neutral with regard to jurisdictional claims in published maps and institutional affiliations. 